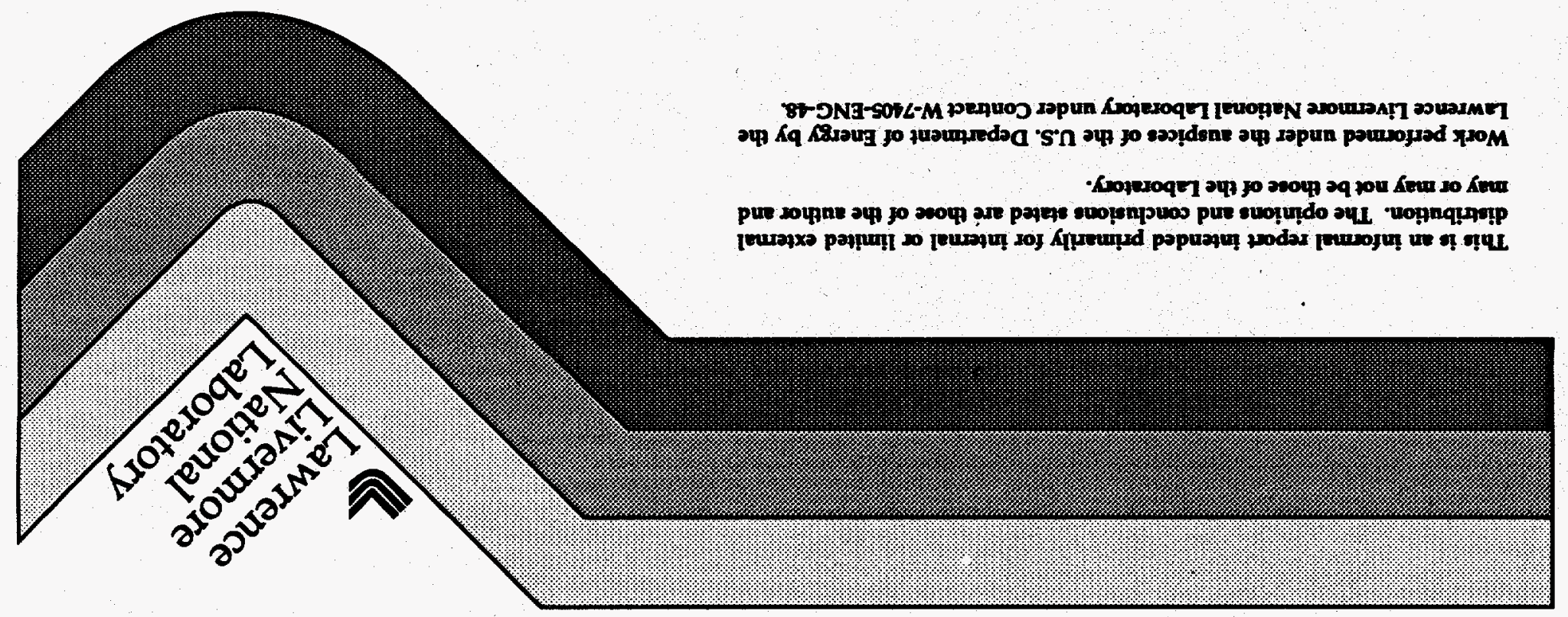

766 I'9l saquaraa

saqə $M$ :S

orunw 'a

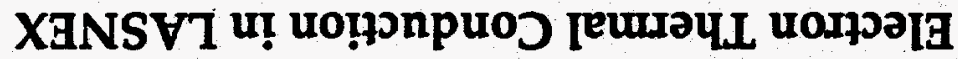




\section{DISCLAIMER}

This document was prepared as an account of work sponsored by an agency of the United States Government. Neither the United States Government nor the University of California nor any of their employees, makes any warranty, express or implied, or aseumes any legal liability or responsibility for the accuracy, completeness, or usefuiness of any information, apparatus, product, or process disclosed, or represents that its use would not infringe privately owned rights. Reference herein to any specific commercial product, process, or service by trade name, trademark, manufacturer, or otherwise, does not necessarily constitute or imply its endorsement, recommendation, or favoring by the United States Government or the University of California. The views and opinions of authors expressed herein do not necessarily state or reflect those of the United States Government or the University of California, and shall not be used for advertising or product endorsement purposes.

This report has been reproduced directly from the best available copy.

Available to DOE and DOE contractors from the Office of Scientific and Technical Information P.O. Box 62, Oak Ridge, TN 37831

Prices available from (615) 576-8401, FTS 626-8401

Available to the public from the National Technical Information Service

U.S. Department of Commerce 5285 Port Royal Rd. Springfield, VA 22161 


\section{DISCLAIMER}

Portions of this document may be illegible in electronic image products. Images are produced from the best available original document. 


\title{
Electron Thermal Conduction in LASNEX
}

\author{
David Munro and Stephen Weber \\ Lawrence Livermore National Laboratory \\ November 30, 1994 \\ Preface
}

This report is a transcription of hand-written notes by DM dated 29 January 1986, transcribed by SW, with some clarifying comments added and details specific to running the LASNEX code deleted. Reference to the esoteric measurement units employed in LASNEX has also been deleted by SW (hopefully, without introducing errors in the numerical constants). The report describes the physics equations only, and only of electron conduction. That is, it does not describe the numerical method, which may be finite difference or finite element treatment in space, and (usually) implicit treatment in time. It does not touch on other electron transport packages which are available, and which include suprathermal electrons, nonlocal conduction, Krook model conduction, and modifications to electron conduction by magnetic fields. Nevertheless, this model is employed for the preponderance of LASNEX simulations.

\section{Introduction}

The following notes are a brief guide to the electron conduction model currently implemented in LASNEX. This model is described in the very nice paper by Dick More and Yim Lee [Phys. Fluids 27, pp. 1273-1286 (84)], with the following exceptions:

(1) In equations (21) and (22) of the paper, there is a typographical error - " $h$ " should be replaced by " $\mathrm{K}$ ". Equation (22) is not quite the final expression for $b_{\text {min }}$ used in LASNEX (Jackson §13.3).

(2) Lee and More do not discuss Spitzer's correction $\delta_{\mathrm{T}}$ to the equations for a "Lorentz plasma" [Physics of Fully lonized Gases, p. 144, eq. 5-48 (Wiley 1962)]. This correction is present in LASNEX, although it is modified for degeneracy effects.

(3) Lee and More do not relate the electron chemical potential $\mu$ to the plasma conditions. LASNEX apparently uses the chemical potential (i.e. - Gibbs free energy per electron) of a degenerate free electron gas, which is a function of the electron temperature and density (i.e. - Fermi energy).

\section{Symbols}

The following symbols will be employed in the discussion. Numerical values are given where appropriate (GJ - gigaJoules). 
$q$-electron heat flux (GJ/ $\left.\mathrm{cm}^{2} / \mathrm{ns}\right)$

$q_{\max }$ - electron flux limit (GJ/ $\left.\mathrm{cm}^{2} / \mathrm{ns}\right)$

$T_{e}$ - electron temperature $(\mathrm{keV})$

$T_{i}$-ion temperature $(\mathrm{keV})$

$\mathrm{K}$ - electron thermal conductivity $(\mathrm{G} / \mathrm{cm} / \mathrm{ns} / \mathrm{keV})$

$n_{e}$ - electron density $\left(\mathrm{cm}^{-3}\right)$

$n_{i}-$ ion density $\left(\mathrm{cm}^{-3}\right)$

$\rho$-plasma density $\left(\mathrm{g} / \mathrm{cm}^{3}\right)$

$\tau_{e i}$ - effective electron ion collision time (ns)

$E_{F}-$ Fermi energy (GJ)

$T_{F}-$ Fermi temperature $(\mathrm{keV})=(2 / 3) \mathrm{E}_{\mathrm{F}} / \mathrm{k}$

$R_{0}$ - interionic spacing $(\mathrm{cm})$

$\lambda_{D H}$ - Debye - Hückel screening length (cm)

$b_{\max }, b_{\min }-$ minimum and maximum impact parameters $(\mathrm{cm})$

$\tau_{p}, \tau_{a}, \tau_{m}, \tau_{\text {floor }}$ - electron ion collision time, electron-neutral collision time, correction for finite melting temperature, and a collision time floor (ns)

\section{Constants}

Following are numerical values of constants appearing in the equations. The equations themselves should all be in cgs units. The constants below are in "practical units" and correspond to the 1986 code. These values differ in the number of digits retained and are not fully consistent, but differences are unlikely to matter for applications. Equations where these numbers are used are shown in \{\} .

$$
\begin{aligned}
& m_{\mathfrak{c}} \text { - electron mass }=9.108 \times 10^{-28} \mathrm{~g} \\
& M_{p} \text { - proton mass }=1.65979 \times 10^{-24} \mathrm{~g} \\
& k \text { - Boltzmann's constant }=1.60208 \times 10^{-25} \mathrm{GJ} \mathrm{keV}^{-1}
\end{aligned}
$$

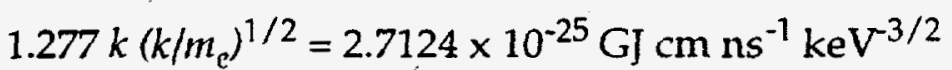

$$
\begin{aligned}
& k^{2} / m_{e}=2.8174 \times 10^{-25} \mathrm{GJ} \mathrm{cm}^{2} \mathrm{keV}^{-2} \mathrm{~ns}^{-2} \\
& \frac{3}{2 \pi \sqrt{2}} \frac{1}{\sqrt{\frac{k}{m_{e}}}\left(\frac{e^{2}}{k}\right)^{2}}=1.2278 \times 10^{19} \mathrm{~ns} \cdot \mathrm{cm}^{-3} \cdot \mathrm{keV}^{-3 / 2} \\
& 3 \pi^{2}\left[\hbar^{2} /\left(2 m_{c} k\right)\right]^{3 / 2}=6.965 \times 10^{-27} \mathrm{~cm}^{3} \mathrm{keV}^{3 / 2}
\end{aligned}
$$




$$
\begin{aligned}
& 3 /(4 \pi)=0.2387 \\
& 4 \pi e^{2} / \mathrm{k}=1 / 5.526 \times 10^{8} \mathrm{keV} \mathrm{cm} \\
& \hbar^{2} /\left(12 m_{e}\right)=6.351 \times 10^{-20} \mathrm{keV} \mathrm{cm} \\
& 4 m_{e} e^{4} /\left(3 \hbar^{2}\right)=0.03628 \mathrm{keV}(4 / 3 \text { Hartrees }=4 / 3 \times 27.2 \mathrm{eV}) \\
& \left(3 k / m_{e}\right)^{1 / 2}=2.297 \mathrm{~cm} \mathrm{~ns}^{-1} \mathrm{keV}^{-1 / 2}
\end{aligned}
$$

\section{Multipliers}

Below are multipliers which are provided for terms in the equations and suggested values, again noting the equation numbers where the multipliers appear.

$c_{1}=1$ - electron conduction multiplier

$c_{2}$ - electron flux limit multiplier $=1.277 / f$, where $f$ is the usual "flux limiter" $\{2\}$

$c_{3}=0$ - two stream flux limit multiplier, set (generally to 1 ) to get an old "two stream" flux limit model which is probably not used nowadays $\{2\}$

$c_{4}=0$ - power of temperature in simple conductivity model; can be used to get Spitzer formula

$c_{5}=0-$ power of density in simple model

$c_{6}=2$ - minimum Coulomb logarithm

$c_{7}=0-$ Coulomb log decrement

$c_{8}=0$ - cross section for electron-neutral collisions $\left(\mathrm{cm}^{2}\right)$, normally neglected $\{14\}$ $c_{9}=1-$ multiplier for solid/liquid collision time

\section{Conductivity}

The heat flux, $q$, and the flux limiter $q_{\max }$ are computed as follows

$$
q=-c_{1} \min \left\{q_{\max } \times \nabla T_{e}\right\}
$$

Note that LASNEX does not use harmonic mean flux limiting for electron conduction. The flux limiter is computed by

$$
q_{\text {max }}=\frac{1.277 n_{e} k T_{e} \sqrt{k T_{e} / m_{e}}}{c_{2}+\frac{0.85108 a^{2}}{1+a^{2} \sqrt{m_{e} n_{e} / p}}}
$$


where,

$$
a=c_{3} \frac{n_{e} T_{e}}{n_{i} T_{i}}
$$

Note that the second term in the denominator in (2) appears only when the two stream flux limiter is used. If either of $c_{4}$ or $c_{5}$ is non-zero, then

$$
\kappa=10^{-6} T^{c_{4}} \rho^{c_{5}}
$$

If $c_{4}=2.5$ and $c_{5}=0$, then the Spitzer formula for conductivity is recovered,

$$
\kappa=8\left(\frac{2}{\pi}\right)^{3 / 2} k \sqrt{\frac{k T_{e}}{m_{e}}}\left(\frac{k T_{e}}{e^{2}}\right)^{2} \frac{\delta_{T}}{Z \log \Lambda}
$$

where

$$
8\left(\frac{2}{\pi}\right)^{3 / 2} k \sqrt{\frac{k}{m_{e}}}\left(\frac{k}{e^{2}}\right)^{2}=4.1635 \times 10^{-5} \mathrm{GJ} \cdot \mathrm{cm}^{-1} \cdot n s^{-1} \cdot k e V^{-7 / 2}
$$

Otherwise, the conductivity is given by

$$
\kappa=n_{e} k\left(\frac{k T_{e}}{m_{e}}\right) \tau_{e i} A \delta_{T^{\prime}}
$$

where

$$
\begin{gathered}
A=\frac{13.566+1.408 \xi+0.565 \xi^{2}}{1+0.525 \xi+0.171 \xi^{2}}, \\
\delta_{T}=\left(\frac{0.0961}{1.2}\right) \frac{1.2+5.4053 x+4.408 x^{2}+0.9067 x^{3}}{0.0961+0.7778 x+1.5956 x^{2}+1.3008 x^{3}},
\end{gathered}
$$

and where

$$
x=\frac{\langle Z\rangle}{\left\langle Z^{2}\right\rangle(1+\xi)}
$$

The mean ionization $\langle Z\rangle=\frac{n_{e}}{n_{i}},\left(n_{i}\right.$ includes neutrals), while $\left\langle Z^{2}\right\rangle=$ the mean square ionization, averaged over the ion species present (weighted by the number of ions).

The quantity $\delta_{T}$ is Spitzer's correction for a non-Lorentz plasma, except that it has been modified by the $(1+\xi)$ factor in $x$ so that $\delta_{T} \rightarrow 1$ for all $Z$ when $\xi \rightarrow \infty$, corresponding 
to a fully degenerate gas. In Claire Max's Physics of Laser Fusion volume (UCRL-53107), she uses $\delta_{T}=\frac{0.24(Z+0.24)}{1+0.24 Z}$, which matches the above expression quite accurately over the full range $0<\mathrm{Z}<\infty$ (assuming $\xi=0$ and $\mathrm{Z}=\left\langle\mathrm{Z}^{2}\right\rangle /\langle\mathrm{Z}\rangle$ ).

The electron-ion collision time, $\tau_{e i}$, and the (dimensionless) electron degeneracy factor, $x$, are computed as follows:

$$
\xi=\left(\frac{0.7531+0.1679 x+0.3108 x^{2}}{1+0.2676 x+0.2280 x^{2}+0.3099 x^{3}}\right) x^{3},
$$

where

$$
\begin{gathered}
x=\sqrt{\frac{E_{F}}{k T_{e}}}, \\
\frac{E_{F}}{k}=\left[3 \pi^{2}\left(\frac{\hbar^{2}}{2 m_{e} k}\right)^{3 / 2} n_{e}\right]^{2 / 3} ; \\
\tau_{e i}=\max \left\{\frac{\tau_{p} \tau_{a}}{\tau_{p}+\tau_{a}}, \tau_{m}, \tau_{\text {floor }}\right\} .
\end{gathered}
$$

The plasma electron-ion collision time $\tau_{p}$ is:

$$
\tau_{p}=\frac{3}{2 \pi \sqrt{2}} \frac{B}{n_{i} \sqrt{\frac{k T_{e}}{m_{e}}}\left(\frac{e^{2}}{k T_{e}}\right)^{2}\left\langle Z^{2}\right\rangle \log \Lambda},
$$

where

$$
B=0.882-0.160 \xi+(0.2+0.671 \xi) \sqrt{\xi} \text {. }
$$

\section{Coulomb logarithm}

The Coulomb logarithm is

$$
\log \Lambda=\max \left\{\frac{1}{2} \log \left(1+\frac{b_{\text {max }}^{2}}{b_{\text {min }}^{2}}\right)-c_{7}, c_{h}\right\},
$$

where

$$
\begin{aligned}
& b_{\max }^{2}=\lambda_{D H}^{2}+R_{n}^{2}, \\
& R_{0}=\left(\frac{3}{4 \pi n_{i}}\right)^{1 / 3},
\end{aligned}
$$




$$
\begin{gathered}
\frac{1}{\lambda_{D H}^{2}}=\frac{4 \pi e^{2}}{k}\left(\frac{n_{e}}{\sqrt{T_{e}^{2}+T_{F}^{2}}}+\frac{n_{i}\left\langle Z^{2}\right\rangle}{T_{i}}\right), \\
T_{F}=\frac{2}{3} \frac{E_{F}}{k}=\text { Fermi temperature, } \\
b_{\text {min }}^{2}=\frac{\hbar^{2}}{12 m_{e} k\left(T_{e}^{2}+T_{F}^{2}\right)}\left[k\left(T_{e}^{2}+T_{F}^{2}\right)^{1 / 2}+\frac{4 m_{e} e^{4}}{3 \hbar^{2}}\left(\frac{\left\langle Z^{2}\right\rangle}{\langle Z\rangle}\right)^{2}\right] .
\end{gathered}
$$

The atomic (neutral) collision time $\tau_{a}$ is given by:

$$
\frac{1}{\tau_{a}}=c_{8} \sqrt{\frac{3 k T_{e}}{m_{e}}} \max \left\{n_{i}-n_{e}, 0\right\},
$$

$\left(n_{i}\right.$ includes the number of neutral ions).

The melting model collision time $\tau_{m}$ is:

$$
\tau_{m}=c_{9} 50 \frac{R_{0}}{\sqrt{\frac{3 k\left(T_{e}^{2}+T_{F}^{2}\right)^{1 / 2}}{m_{e}}}} \frac{T_{m}}{T_{e}}\left(\begin{array}{c}
1 ; \text { if }\left(T_{e} \leq T_{m}\right) \\
0.74 ; \text { if }\left(T_{e}>T_{m}\right)
\end{array}\right),
$$

where the melting temperature $T_{m}$ is given by

$$
T_{m}=(0.32 e V) \frac{\xi^{2 b+10 / 3}}{(1+\xi)^{4}}
$$

and where

$$
\begin{aligned}
& \xi=9 Z_{\text {nuc }}^{0.3} M_{p} n_{i}, \\
& b=0.6 Z_{\text {nuc: }}^{1 / 9} \\
& Z_{\text {nuc }}=\frac{\rho}{2.5 M_{p} n_{i}} .
\end{aligned}
$$


Finally, the floor collision time $\tau_{\text {floor }}$ is given by the time to move an interionic spacing:

$$
\tau_{\text {floor }}=\frac{R_{0}}{\sqrt{\frac{3 k}{m_{e}} \sqrt{T_{e}^{2}+T_{F}^{2}}}} .
$$

